\title{
Ethnic differences in perinatal mortality
}

\author{
P. B. TERRY \\ F.R.C.S.E., M.R.C.O.G.
}

R. G. CONDIE

M.D., M.R.C.O.G.

Dudley Road Hospital, Birmingham B18 7QH

\section{Summary}

Of the 3869 normally formed, singleton deliveries in Dudley Road Hospital in 1979, 3690 were to either European (1644), Indian (1087), Pakistani (556) or West Indian (403) mothers. The perinatal mortality rates in the Indian group with birth weights of 2000 $2999 \mathrm{~g}$ and $3000-3999 \mathrm{~g}$ were higher than in any of the other ethnic groups $(11.5 / 1000$ and $6 \cdot 7 / 1000$ respectively).

\section{Introduction}

Perinatal epidemiology has been recognized as a useful tool in the identification of obstetrical risk factors. Most workers believe that the identification of these factors has helped to reduce the perinatal mortality rate and improve the 'quality' of infants born. Little work has been done on the effect of the ethnic origin of the mother in the absence of differing obstetric and paediatric care although recently ethnic differences have emerged as an apparently important factor in perinatal mortality (Terry, Condie and Settatree, 1980).

Dudley Road Hospital, Birmingham, serves an inner-city, multi-racial population. Birth-weightspecific perinatal mortality rates were analysed in the main ethnic groups attending this Department.

\section{Patients and methods}

Information on maternal ethnic origin, birth weight, perinatal mortality, multiple births an $\overline{\mathscr{B}}$ congenital malformations was obtained from the 3 . labour ward register. There was a total of 4026 deliveries in 1979. All multiple births, perinatabs deaths and infants with major congenital abnorma- $-\mathrm{A}$ lities were excluded from the analysis.

\section{Results}

Of the 3869 deliveries in the series, $1644(42 \%)$ were European, $1087(28 \%)$ Indian, $556(14 \%)$ Pakistani and 403 (10\%) West Indian. There werê 54 corrected perinatal deaths; 14 were European, 23 Indian, 7 Pakistani and 6 West Indian. The perinatal mortality rates in the $<1000 \mathrm{~g}$ births we uniformly high in all the ethnic groups. In theo $1000-1999 \mathrm{~g}$ births the perinatal mortality re was higher in the Pakistani group (545/1000) thano in the other ethnic groups. In the 2000-2999 $\mathrm{g}$ and $3000-3999 \mathrm{~g}$ births the perinatal mortalityo rate in the Indian ethnic group, at $11 \cdot 5 / 1000$ and $\frac{\mathscr{C}}{\mathbb{D}}$ $6 \cdot 7 / 1000$, was appreciably higher than in any of the other ethnic groups (Table 1).

\section{Discussion}

Differences in the birth-weight-specific perinatal mortality rates in different ethnic groups have been흠 observed by other workers. An example is the observation of low birth weight-specific perinatal $\frac{3}{3}$ mortality rates in American blacks as compared. with whites (National Center for Health Statistics, 을

TABLE 1. Ethnic distribution of birth-weight-specific perinatal mortality rates/1000 births (Figures in parentheses represent number of singleton deliveries)

\begin{tabular}{lccccc}
\hline & \multicolumn{5}{c}{ Birth weight (g) } \\
& $<1000$ & $1000-1999$ & $2000-2999$ & $3000-3999$ & $>3999$ \\
\hline Indian (1087) & 750 & 266 & 11.5 & 6.7 & 0 \\
Pakistani (556) & 1000 & 545 & 0 & 0 & 0 \\
West Indian (403) & 1000 & 222 & 0 & 0 & 0 \\
European (1644) & 1000 & 286 & 2.4 & 1.9 & 0 \\
\hline
\end{tabular}

$0032-5473 / 81 / 1200-0790 \$ 02.00$ (C) 1981 The Fellowship of Postgraduate Medicine 
1972; North and MacDonald, 1977). This observation is not surprising if American blacks, for some genetic reason, produce smaller fetuses than do the white group. It is not clear why, as in this study, the Indian ethnic group, who tend to produce smaller fetuses (Terry et al., 1980), have a higher perinatal mortality rate in the high birth-weight groups. Environmental factors such as dietary deficiencies may be contributory.

\section{References}

National Center for Health Statistics (1972) A study of infant mortality from linked records, Rockville, Md. Vital Health Statistics Series 20, No. 12.

NoRTH, A.F. \& MACDoNALD, H.M. (1977) Why are neonatal mortality rates lower in small black infants than in white infants with similar birth weight? Journal of Pediatrics, 90, 809.

Terry, P.B., Condie, R.G. \& Settatree, R.S. (1980) Analysis of ethnic differences in perinatal statistics. British Medical Journal, 2, 1307. 